\title{
Pencapaian Keluarga Sakinah melalui Pemberdayaan Ekonomi di Desa Buddagan Kecamatan Pademawu
}

\author{
${ }^{1}$ Erie Hariyanto, Maimun, Ainurrahman Hidayat \\ Institut Agama Islam Negeri Madura, Jl. Raya Panglegur Km. 4 Pamekasan 69371 \\ 1erie.mh2@gmail.com
}

\begin{abstract}
The number of divorce cases in Indonesia, child abuse, violence, and criminal acts in the household are proof that in realizing the Sakinah family requires the involvement of several parties; parents, the Religious Affairs, and the village government. This community service theme has a correlation with the District Office of Religious Affairs (KUA) in Pademawu District, Pamekasan Regency. The functions and duties were to deal with quite complex issues concerning all religious matters including marriage, divorce, divorce, reconciliation. "Achievement of Sakinah Families through Economic Empowerment in Buddagan Village, Pademawu District". The study is intended to minimize divorce and early marriage cases in Pademawu community, especially in Buddagan. Economic factors are one important factor in navigating the Sakinah family. The need for solid cooperation between parents, the community, and the KUA in order to strengthen the Sakinah family in various aspects including Economy, Education, and Culture. In the field of economic empowerment, it is necessary to involve the local government and the government of the province of East Java to support capital and job training.
\end{abstract}

Keywords: Family Empowerment, Sakinah Family, KUA

\begin{abstract}
Abstrak
Banyaknya kasus perceraian di Indonesia, terjadinya pelecehan anak, kekerasan dan tindak kriminal dalam rumah tangga adalah bukti bahwa dalam mewujudkan keluarga sakinah butuh keterlibatan beberapa pihak. Seperti orang tua, KUA dan pemerintah desa menjadi komponen yang penting dalam membentuk keluarga sakinah mawadah warahmah. Tema Pengabdian kepada masyarkat ini memiliki korelasi dengan Kantor Urusan Agama Kecamatan (KUA) di Kecamatan Pademawu Kabupaten Pamekasan. Adapun fungsi dan tugasnya waktu itu adalah menangani persoalan yang cukup kompleks mengenai seluruh urusan keagamaan termasuk didalamnya adalah Nikah, Talak, Cerai, Rujuk. "Pencapaian Keluarga Sakinah Melalui Pemberdayaan Ekonomi di Desa Buddagan Kecamatan Pademawu". Adapun tujuan penyuluhan ini ialah untuk mengurangi adanya perceraian dan pernikahan dini oleh masyarakat pademawu khususnya masyarakat Buddagan. Faktor ekonomi menjadi salah satu faktor terpenting dalam mengarungi keluarga sakinah kedepan. Perlunya kerjasamanya yang padu antara orang tua, masyarkat dan KUA dalam rangka memperkuat keluarga sakinah dalam berbagai aspek diantaranya Ekonomi, Pendidikan dan Budaya. Dalam bidang pemberdayaan ekonomi perlu keterlibatan pemerintah daerah dan pemerintah propensi jawa timur untuk mendukung permodalan, pelatihan kerja.
\end{abstract}

Kata Kunci: Pemberdayaan Keluarga, Keluarga Sakinah, KUA 


\section{Pendahuluan}

Keluarga hanya bisa terbentuk melalui proses pernikahan dan itu merupakan fitrah manusia, sebagaimana fitrah manusia lainnya dalam mendambakan pasangan. Untuk menjembatani hal tersebut, agama mensyari'atkan dijalinnya pertemuan antara laki-laki dan perempuan hingga terlaksana pernikahan dan kerisauan yang dialami pria dan wanita sebelum menikah beralih menjadi ketentraman (Shihab, 2001). Oleh karena itu, dalam Islam pernikahan sangat dianjurkan bagi mereka yang mampu (alNaysaburî, 2008: 10). Agar tujuan pernikahan dalam hal memperoleh ketenangan dan ketentraman dapat tercapai dengan baik (Musawwamah, 2010: 13). Keluarga yang diliputi ketenteraman, kedamaian, ketenangan, dan kebahagiaan itu disebut sebagai keluarga sakinah (PP. Aisyiah, 2015).

Sebagaimana telah disinggung diatas, peran keluarga sebagai kontrol sosial dan bahkan dalam menentukan arah tujuan bangsa adalah sangat sentral. Banyaknya kasus perceraian di Indonesia, terjadinya pelecehan anak, kekerasan dan tindak kriminal dalam rumah tangga adalah bukti bahwa dalam mewujudkan keluarga sakinah butuh keterlibatan beberapa pihak. Seperti orang tua, KUA dan Pemerintah desa menjadi komponen yang penting dalam membentuk keluarga sakinah mawadah warahmah.

Tema Pengabdian kepada masyarkat ini memiliki korelasi dengan Kantor Urusan Agama Kecamatan (KUA) di kecamatan Pademawu Kabupaten Pamekasan. Adapun fungsi dan tugasnya waktu itu adalah menangani persoalan yang cukup kompleks mengenai seluruh urusan keagamaan termasuk didalamnya adalah NTCR. Karenanya pelaksana utama KUA sering disebut moskee Personeel dan penghulu.

Kantor urusan Agama Kecamatan Pademawu merupakan salah satu dari 13 KUA yang ada di Kabupaten Pamekasan. Gedung Kantor urusan Agama Kecamatan Pademawu di bangun pada areal tanah dengan luas kurang lebih $1800 \mathrm{~m}^{2}$. Tanah tempat KUA tersebut dibangun merupakan tanah wakaf dengan nomor 35.28.02.11.1.00164 tertanggal 19 September 1991 atas nama pemerintah Desa Pademawu Barat Kecamatan Pademawu Kabupaten Pamekasan, yang dalam sertifikat tanah wakafnya menyatu dengan tanah masjid Baitul Muttaqien.

KUA Kecamatan Pademawu sampai hari ini sudah lebih dari 20 kali berganti kepemimpinan, karakter dan model kepemimpinan masing-masing telah banyak mewarnai dengan tinta emas sehingga KUA berganti tahun dan pereode semakin baik dibawah kepemimpinan Drs. H. Jalaluddin, M.Si. Kantor Urusan Agama Kecamatan Pademawu diharapkan bisa lebih maju lagi. pada tahun ini direncanakan untuk melengkapi software dan hardware yang lebih adaptif progresif, hal ini untuk mengimbangi kebutuhan dan perkembangan teknologi yang terus meroket, untuk memenuhi kebutuhannya, saat ini telah diusulkan ke Kantor Kementerian Agama Wilayah Provinsi Jawa Timur untuk renovasi total (Wafi, t.t.).

KUA Pademawu mewilayahi 22 Desa yang tersebar di Kecamatan Pademawu. Adapun ke-22 Desa tersebut adalah sebagai berikut: Pademawu Barat, Pademawu Timur, Bunder, Tanjung, Padelegan, 
Majungan, Pagagan, Badduri, Jarin, Prekbun, Sopaah, Buddih, Durbuk, Sumedangan, Lemper, Buddagan, Buddagan, Baru rambat timur, Lawangan daya, Sentol, Tambung dan dasok.

Dalam kegiatan Pengabdian Masyarakat (PKM) Prodi Hukum Ekonomi Syariah ditempatkan di desa Buddagan yang merupakan salahsatu dari 22 desa di kecamatan pademawu yang menurut hasil penelitian terdahulu memiliki tingkat kawin di usia muda relatif tinggi dibandikan dengan desadesa yang lain.

Visinya Amanah dalam mengemban tugas dan prima melayani umat menuju terwujudnya masyarakat pademawu yang agamis dan berakhlak mulia. Misi untuk Meningkatkan Kualitas pemahaman penghayatan dan pengamalan moral serta etika yang berdasarkan Agama melalui: (1) Meningkatkan kualitas pelayanan kepenghuluan dan pencatatan NR; (2) Meningkatkan pelayanan yang prima pada masyarakat; (3) Meningkatkan pembinaan keluarga sakinah dengan cara mengoptimalkan peran dan BP4 Kecamatan; (4) Meningkatkan pelayanan dan pembinaan pada lembaga keagamaan dan ibadah sosial (IBSOS); (5) Meningkatkan kualitas pelayanan dan bimbingan manasik haji; (6) Meningkatkan hubungan yang sinergek antar instansi (lintas sektoral) (Zuhri, t.t.).

Kegiatan pelayanan nikah/rujuk di KUA Kecamatan Pademawu tidak lepas dari koridor hukum sebagaimana uraian awal pada bab terdahulu, yaitu berupa undang-undang dengan segala peraturan organisatoris dibawahnya. Untuk itu secara prosedural pelayanan nikah/rujuk kepada masayrakat harus melalui mekanisme pelayanan yang diatur sebagai berikut:

a. Calon pengantin atau wali orang lain yang ditunjuk berdasarkan surat kuasa khusus, memberitahukan kehendak nikahnya kepada penghulu di KUA (KMA No. 77/2004 tentang pencatat nikah/rujuk).

b. Bersamaan dengan pemberitahuan kehendak nikah, yang bersangkutan membawa surat-surat yang diperlukan, seperti akta kelahiran atau surat keterangan asal-usul (formulir model N-7 KMA No. 9/1990 psl 8)

c. Penghulu berkewajiban mengadakan penelitian dan pemeriksaan nikah kepada calon mempelai dan wali berkaitan dengan pemenuhan syaratsyarat perkawinan sesuai dengan peraturan yang berlaku (PT. No. 9/1975 psl 6 (1). Jo KMA No. 2/1990 psl 7) dalam pemeriksaan nikah tersebut sekaligus diberikan nasehat perkawinan dari BP-4 kecamatan

d. Setelah syarat-syarat terpenuhi, penghulu, calon penganten dan wali menandatangani hasil pemeriksaan dalam daftar pemeriksaan nikah (NB), serta ditambah dengan dua orang saksi setelah pelaksanaan nikah

e. Penghulu berkewajiban mencatat peristiwa nikah di akta nikah/rujuk, (model N/register Nikah) dan kutipan akta nikah (surat nikah /NA) dapat diberikan langsung sesaat setelah pelaksanaan nikah (surat dirjen BIUH No. D/Pw. 01/3913/91). 


\section{Pelaksanaan Pegabdian Kepada Masyarakat}

Upaya pemberdayaan yang ditawarkan diarahkan untuk mendukung fungsi keluarga yaitu keagamaa, budaya, cinta kasih, perlindungan, reproduksi dan kesehatan, pendidikan, ekonomi, dan lingkungan dengan lebih menekankan kepada aspek pemberdayaan ekonomi keliarga untuk mencaoai keluarga sakinah.

Sekilas, letak geografis yang kami tempati di kecamatan pademawu adalah desa Buddagan lebih tepatnya lagi di dusun Buddagan. Dusun Buddagan tempat Pengabdian kepada Masyarakat (PKM) berlangsung, secara kasat mata dusun Buddagan merupakan dusun yang terluas yang ada di desa Buddagan dan dusun Buddagan mempunyai berbagai potensi dalam bidang perekonomian, pendidikan, dan agama.

Hampir semua tanah di desa Buddagan sangat baik untuk lahan pertanian, sehingga mulai musim hujan sampai musim kemarau masyarakat Buddagan melakukan cocok tanam dari berbagai jenis tanaman. Mulai dari padi, jagung, dan tembakau. Selain lahan pertanian di jadikan penghasilan masyarakat Buddagan ada yang menjadi pegawai dan juga wiraswasta.

Sedangkan dalam sektor atau potensi pendidikan, di desa Buddagan banyak terdapat beberapa lembaga pendidikan dari tingkat TK, $\mathrm{SD} /$ sederajat, SMP/ sederajat, dan SMA/ sederajat. Sehingga, hal ini berpotensi untuk meningkatkan Sumber Daya Manusia (SDM) masyarakat desa Buddagan.

Pada tanggal 12 November 2018 dilaksanakan kegiatan penyuluhan dengan tema "Pencapaian Keluarga Sakinah melalui Pemberdayaan Ekonomi di Desa Buddagan Kecamatan Pademawu". Adapun tujuan penuluhan ini ialah Untuk mengurangi adanya perceraian dan pernikahan dini oleh masyarkat pademawu khususnya masyarkat Buddagan.

Kegiatan ini dimulai tepat pada pukul 15.00 WIB di Balai desa Buddagan. Penyuluhan ini dihadiri oleh kepala desa, perangkat desa dan masyarakat sekitar dengan jumlah kurang lebih sebanyak 40 orang yang didominasi oleh karantaruna dan ibu-ibu PKK. turut hadir mengikuti kegiatan penyuluhan ini diantaranya ialah Ibu Dr. Umi Supratiningih SH.M.Hum, Bapak Dr. Erie Hariyanto, M.H, Bapak Dr, Ainurrahman Hidayat, M.Hum dan Bapak Dr. Maimun, M.Ag yang ikut berpartisipasi.

Dalam penyampaiannya, pemateri menyampaikan banyak hal terutama himbauan kepada orang tua untuk menjalin komunikasi yang baik dengan anak sehingga antara orang tua dan anak akan saling terbuka. Hal ini dianjurkan sebagai cara antisipasi terjerumusnya generasi muda ke dalam pergaulan bebas. Berbicara tentang keluarga, beliau juga menyampaikan jika dalam keluarga terjadi KDRT ataupun pelecehan dan sebagainya hendaknya melaporkan kepada pihak yang berwajib. Hal ini dianjurkan sebagai antisipasi merajalelanya permasalahan keluarga sehingga berakibat fatal.

Dalam paparanya Bapak Ainurrahman mepaprkan tentan posisi wanita dimana pertama Wanita sebagai istri, wanita harus memposisikan diri sebagai istri, yakni seorang istri harus merasa bahwa dirinya adalah milik 
dan hanya diabadikan untuk suaminya dalam hal cinta kasih bukan kepada orang lain, serta menjaga dan membelanjakan harta dan nafkah suami secara bijaksana, kedua wanita juga harus menumbuhkan suasana yang harmonis, tampil bersih, memikat mampu mendorong suami untuk hal-hal yang positif. Peran wanita dalam mewujudkan keluarga sakinah harus mempersiapkan segala sesuatunya dengan baik, lalu mengolah sebuah keluarga dalam naungan agama yang kuat, agar menjadi keluarga yang berkualitas supaya menghasilkan generasi yang tidak hanya pandai namun juga taat terhadap agamanya.

Ketiga untuk mengatasinya diperlukan upaya dan strategi mengintegrasikan gender ke dalam arus pembangunan dengan cara menempatkan perempuan sebagai subjek pembangunan dan menghilangkan faktor kendala yang dihadapi perempuan dalam pembangunan dengan melakukan kegiatan analisis dan evaluasi. Untuk melihat peran perempuan dapat dijabarkandalam 6 aspek (1) sejauhmana perempuan terlibat dalam program-program pembangunan, (2) sejauhmana kualitas tenaga kerja perempuan. (3) hambatan-hambatan apa saja yang dihadapi perempuan dalam kegiatan pembangunan (4) upaya-upaya apa saja yang diperlukan untuk meningkatkan kualitas dan peran perempuan; (5) faktor apa sajakah yang dominan berpengaruh terhadap hubungan gender dan (6) bagaimana pemecahan masalah yang dihadapi perempuan. Maka dengan kerangka ini tentunya akan dapat dihasilkan suatu identifikasi sejauhmana peranan perempuan dalam pembangunan dewasa ini.

Beberapa wakta menarik diungkap oleh narasumber terkait perempuan:

a. Salah satu indikator integrasi perempuan dalam pembangunan adalah tingkat partisipasi angkatan kerja (TPAK) perempuan disemua bidang lapangan kerja sebagai politikus, PNS, karyawan, buruh perusahaan termasuk petani, hingga tahun 1998 saja mencapai 40,2 persen.

b. PKT-RSCM Jakarta: tiap hari ada minimal 2 atau 3 kasus baru, terbanyak kasus kekerasan seksual (pada anak dan dewasa), KDRT disusul lainlain.

c. Rifka Annisa WCC Yogyakarta: terbanyak kekerasan terhadap istri di masa pacaran lalu kekerasan seksual.

d. LBH APIK Jakarta: 600 - 1000/tahun terbanyak kasus KDRT disusul bentuk lain.

Berangkat dari kesadaran tentang adanya kekerasan dalam relasi personal yang umumnya lebih banyak terjadi pada perempuan. Kerentanan khusus pada perempuan dan anak dalam situasi normal maupun konflik/perang Kekerasan sebagai akibat system nilai budaya dan struktur masarakat yang menempatkan perempuan sebagai objek pendamping, lebih rendah, hak milik dan menempatkan pria dewasa sebagai standar penentu paling penting.

Kegiatan ini didesain sebagai forum interaktif, artinya masyarakat dipersilahkan untuk memberikan pertanyaan kepada pemateri agar dapat di diskusikan secara bersama bersama. Hal ini dilakukan sebagai cara agar 
tujuan dari pelaksanaan penyuluhan dapat tercapai dengan baik. Acara ini berjalan dengan lancar, sebagai bentuk antusias masyarakat terhadap kegiatan yang diadakan masyarakat mengikuti rentetan acara dengan hikmat. Hingga pukul 17.00 WIB acara selesai.

\section{Analisis Keberhasilan Situasi Kondisi Saat Ini}

Berdasarkan Peraturan Dirjen Bimas Islam Nomor : Dj.11/491 Tahun 2009 tentang Kursus Calon Pengantin, bahwa tujuan dari kursus ini adalah dalam rangka meminimalisir tingginya angka perselisihan, perceraian dan kekerasan dalam rumah tangga. Salah satu sebab munculnya masalah tersebut adalah rendahnya pengetahuan dan pemahaman calon pengantin tentang kehidupan rumah tangga/keluarga. Kursus Catin ini dilaksanakan sekurang-kurangnya 24 jam pelajaran meliputi materi:1.Tatacara dan prosedur perkawinan, 2.Pengetahuan Agama, 3.Peraturan Perundangundangan di bidang perkawinan dan keluarga, 4. Hak dan kewajiban suami isteri, 5. Kesehatan reproduksi, 6.Manajemen Keluarga, dan 7.Psikologi perkawinan dan keluarga.

Sebagai tindak lanjutnya telah lahir sejumlah perundang-undangan yang mengatur dan berusaha melahirkan keluarga sakinah; Kursus Pra Nikah, Kursus Calon Pengantin, dan penyuluhan untuk sosialisasi berbagai kebijakan dan peraturan kepad masyarakat, yakni:

a. UU No. 52 tahun 2009 tentang Perkembangan Kependudukan dan Pembangunan Keluarga;

b. UU No. 1 tahun 1974 tentang Perkawinan;

c. PP No. 21 tahun 1994 tentang Penyelenggaraan Pembangunan Keluarga Sejahtera;

d. Putusan Menag. R.I. (PMA) No. 3 tahun 1999, tentang Pembinaan Gerakan Keluarga Sakinah;

e. Kep. Dirjen. Bimas Islam dan Urusan Haji No. D/71/1999, tentang Juklak Pembinaan Gerakan Keluarga Sakinah;

f. Peraturan Dirjen Bimas Islam No. DI.II/491 tahun 2009 tentang Kursus Calon Pengatin;

g. Peraturan Direktur Jenderal Bimbingan Masyarakat Islam No.: Dj.ii/542 tahun 2013, tentang Pedoman Penyelenggaraan Kursus Pra Nikah;

h. Surat edaran Mendagri No. 400/564/II/Bangda Tahun 1999 tentang Pelaksanaan Pembinaan Gerakan Keluarga Sakinah (GKS).

Dari pemerintah sudah menerbitkan sejumlah perundang-undangan tersebut telah dilaksanakan beberapa program dan kegiatan tinggal bagaimana implementasinya saja:

a. Telah dibentuk Badan Penasehatan, Pembinaan dan Pelestarian Perkawinan (BP4) untuk melakukan pembinaan perkawinan dan menurunkan angka perceraian.

b. Telah diselenggarakan Kursus Pra Nikah dan Kursus Calon Pengantin di beberapa tempat. 
c. Telah dibentuk Badan Penyuluh untuk mensosialisasikan berbagai kebijakan pemerintah dan peraturan di bidang keluarga.

Langkah Penyelenggaraan Kursus Pra Nikah dengan melakukan: (a) Identifikasi kondisi BP4 dan/atau Institusi lain sebagai penyelenggara Kursus; dan (b) kesiapan pelaksana Kursus Pra Nikah sebagai awal permulaan penyelenggaraan kursus cukup, dilaksanakan oleh BP4 dan/atau Institusi lain tingkat kabupaten/kota, dengan catatan BP4 atau institusi lain tingkat Kecamatan yang mempunyai kemampuan diberikan kesempatan untuk menyelenggarakan Kursus Pra-Nikah.

Penyuluhan hukum tentang Pencapaian Keluarga Sakinah Melalui Pemberdayaan Ekonomi Di Desa Buddagan Kecamatan Pademawu mendaptkan tanggapan yang antusias, forum bukan hanya pada waktu acara namun juga diikuti konsultasi peserta kepada narasumber secara personal tentang persoalan-persoalan rumah tangga terutama dalam hal pengelolaan keuangan.

\section{Temuan}

Tujuan BP4 adalah untuk mempertinggi kualitas perkawinan, mencegah perceraian sewenang-wenang dan mewujudkan rumah tangga yang bahagia sejahtera menurut tuntunan agama Islam. Sejak ditetapkan berdasarkan KMA No. 85 tahun 1961, BP4 menjadi satu-satunya badan yang bergerak dalam bidang penasehatan perkawinan, talak dan rujuk, dan upaya untuk mengurangi angka perceraian yang terjadi di Indonesia.

Pada tahun 1999 telah lahir aturan dan program keluarga sakinah dan kursus Pra Nikah, dengan Putusan Menag. R.I. (PMA) No. 3 tahun 1999, tentang Pembinaan Gerakan Keluarga Sakinah; Kep. Dirjen. Bimas Islam dan Urusan Haji No. D/71/1999, tentang Juklak Pembinaan Gerakan Keluarga Sakinah; dan Surat edaran Mendagri No. 400/564/III/Bangda Tahun 1999 tentang Pelaksanaan Pembinaan Gerakan Keluarga Sakinah (GKS).

Sementara itu, dengan meminjam teori Tindakan Sosial Max Weber, boleh disebut banyak untuk tidak menyebut mayoritas, pelaksanaan perkawinan masyarakat Indonesia masuk pada Tindakan Sosial Tradisional atau Tindakan Sosial Afektif. Dimana Max Weber menyelompokkan tindakan sosial menjadi empat, yakni; Tindakan Rasionalitas Instrumental, Tindakan Rasional Nilai, Tindakan Afektif, dan Tindakan Tradisional.

Tindakan Rasionalitas Instrumental merupakan tindakan sosial yang dilakukan seseorang didasarkan atas pertimbangan dan pilihan sadar yang berhubungan dengan tujuan tindakan itu dan ketersediaan alat yang dipergunakan untuk mencapainya. Tindakan Rasional Nilai memiliki sifat bahwa alat-alat yang ada hanya merupakan pertimbangan dan perhitungan yang sadar, sementara tujuan-tujuannya sudah ada di dalam hubungannya dengan nilai-nilai individu yang bersifat absolut. Tipe Tindakan Afektif lebih didominasi perasaan atau emosi tanpa refleksi intelektual atau perencanaan sadar. Tindakan afektif sifatnya spontan, tidak rasional, dan merupakan 
ekspresi emosional dari individu. Sedangkan Tindakan Tradisional, seseorang memperlihatkan perilaku tertentu karena kebiasaan yang diperoleh dari nenek moyang, tanpa refleksi yang sadar atau perencanaan. Intinya, bahwa dua yang pertama mempunyai pertimbangan, ada kesadaran, ada tujuan, dan mempertimbangkan potensi, kemampuan dan sarana, sementara dua yang terakhir tanpa pertimbangan, tanpa sadar dan tanpa tujuan terencana.

Ada orang melaksanakan perkawinan didorong oleh rasa bingung; bingung kanera sudah lulus sekolah SLTP atau SLTA, dan ada juga di beberapa tempat lulus SD, sementara tidak dapat melanjutkan sekolah ke jenjang yang lebih tinggi. Orang tua bingung melihat anaknya yang kesehariannya hanya mondar mandir. Orang tua bingung karena anaknya sudah hamil. Masih banyak kebingungan lain yang menjadi latar belakang mengapa ada perkawinan. Walhasil perkawinan dilakukan bukan untuk mencapai tujuan membangun keluaga sejahtera atau keluarga tahan, tetapi untuk menghilangkan rasa bingung. Dalam kasus-kasus semacam ini jelas tidak ada perencanaan (by design). Maka tidak berlebihan kalau kemudian juga berakhir dengan kebingunngan, bermasalah, bercerai, dan hanya by accident yang dapat bertahan dan sejahtera.

Perlu perencanaan keuangaan keluarga sebelum melangsungkan perkawinan, dari latar belakang inilah kami bermaksud melakukan Pemberdayaan kepada masyarkat. Sehingga suami-istri mengetahui tentang hak dan kewajibannya sehingga ealam pengelolaan rumahtangga akan harmonis. Perlu adanya upaya yang serius dan berkesinambungan untuk mendukung program pemerintah meciptakan keuarga sakinah mawadah salahsatunya dengan melakukan penyuluhan kepada masyarakat.

\section{Penutup}

Menanggulagi tipologi perkawinan masyarakat Indonesia yang masih banyak dilakukan di usia dini dan tanpa persiapan yang memadai dengan melakukan memberikan penyuluhan hukum tentang keluarga sakinah utamanya dalam bidang penguatan ekonomi keluarga dengan pembedayaan ekonomi keluarga calon pengantin yaitu untuk memberikan bekal pengetahuan kepada para calon suami dan isteri bagaimana cara mengharungi dan membangun keluarga, sehingga suami dan isteri dapat menjalankan fungsi keluarga dengan baik dimana faktor ekonomi menjadi salahsatu faktor terpenting dalam mengarungi keluarga sakinah kedepan. Perlunya kerjasamanya yang padu antara orang tua, masyarkat dan KUA dalam rangka memperkuat keluarga sakinah dalam berbagai aspek diantaranya Ekonomi, Pendidikan dan Budaya. Dalam bidang pemberdayaan ekonomi perlu keterlibatan pemerintah daerah dan pemerintah propensi jawa timur untuk mendukung permodalan, pelatihan kerja. 


\section{Daftar Pustaka}

al-Naysaburî, A.-I. M. I. al-Hajjâji al-Qusyayri. (2008). Shahîh Muslim. Beirut: Dâr al-Kutub 'Ilmiyah.

Badan Penasihatan Pembinaan dan Pelestarian Perkawinan (BP4). (2008). Perkawinan \& Keluarga. Jakarta: BP4.

. (2011). Tuntunan Praktis Rumah Tangga Bahagia. Provinsi Jawa Timur: BP4.

Departemen Agama RI. (1986). al-Qur'an dan Terjemahnya. Jakarta: Intermassa.

. (2004). Pedoman Pembantu Pegawai Pencatat Nikah, Jakarta: Proyek Peningkatan Tenaga Keagamaan.

. (2005). Membina Keluarga Sakinah, Jakarta: Ditjen Bimas Islam dan Penyelenggaraan Haji Direktor Urusan Agama Islam.

. (2008). al-Qur'an dan Terjemahannya Bandung: CV Penerbit Diponegoro.

- (2006). Tanya Jawab Seputar Keluarga Sakinah, Jakarta:

Depertemen Agama RI, Direktorat Jenderal Bimbingan Masyarakat Islam, Direktorat Urusan Agama Islam dan Syariah.

. (2010). Pegangan Calon Pengantin, Surabaya: Direktorat Jenderal Bimbingan Masyarakat Islam dan Penyelenggaraan Haji Kementerian Agama RI.

. (2010). Hasil Munas BP4 XIII/2004 dan Pemilihan Keluarga Sakinah Teladan Tingkat Nasional, Jakarta.

(2010). Pedoman Konselor Keluarga Sakinah, Surabaya:

Direktorat Jenderal Bimbingan Masyarakat Islam dan

Penyelenggaraan Haji Kementerian Agama.

Agama RI.

(2006). Seputar Keluarga Sakinah, Jakarta: Depertemen

. (2011). Tuntunan Praktis Rumah Tangga Bahagia, Surabaya:

Badan Penasehat Pembinaan dan Pelestarian Perkawinan (BP-4),

. (2010). Tuntunan Keluarga Sakinah Bagi Remaja Usia Nikah,

Kanwil Propinsi Jwa Timur.

Musawwamah, S. (2010). Hukum Perkawinan. Pamekasan: STAIN Pamekasan Press.

Mustafa, A. M. (2013). Di sini Kita Harmoni di Surga Kita Bahagia, Jawa Tengah: Inas Media.

PP. Aisyiah. (2015). Tuntunan Menuju Keluarga Sakinah. Yogyakarta: PP. Aisyiah.

Shihab, M. Q. (2001). Tafsir Al-Misbah. Jakarta: Lentera Hati.

Wafi, H. A. (t.t.). Staf atau Penghulu KUA Kec. Pademawu [Wawancara Langsung].

Zuhri, S. (t.t.). Staf atau Penghulu KUA Kec. Pademawu [Wawancara Langsung]. 